\title{
Case Studies Approach in Tourism Destination Branding Research
}

\author{
S.F. Adeyinka-Ojo ${ }^{1}$, V. Nair ${ }^{2}$, C. Khoo-Lattimore ${ }^{3}$ \\ ${ }^{1,2,3}$ School of Hospitality, Tourism and Culinary Arts, Taylor's University, Lakeside Campus, \\ Malaysia \\ ${ }^{3}$ Department of Tourism, Sport and Hotel Management, Griffith Business School, Griffith University, \\ Australia
}

\begin{abstract}
A review of literature indicates that there are different types of qualitative research methods such as action research, content analysis, ethnography, grounded theory, historical analysis, phenomenology and case study. However, which approach is to be used depends on several factors such as the nature and objectives of the research. The aim of this paper is to focus on the research methodology aspects of applying case study as a research approach and its relevance in tourism destination branding research specifically on a single case study (SCS) context. There are arguments that the SCS is a weak research strategy. Some of the potentials or shortcomings highlighted in the literature include the primitive nature of SCS, flexibility of sample technique, data collection method and data analysis. Others include lack of rigour, reliability, validity, credibility of findings and generalisation. This paper has adopted content analysis of the literature on tourism destination branding. Findings indicate that the quality of SCS can be verified using specific case study tactics for four design tests such as validity (construct, internal and external); and reliability using the case study protocol. Theoretical implication suggests that SCS is an empirical enquiry use to understand complex phenomena and favoured by practitioners.
\end{abstract}

\section{Introduction}

In achieving the main aim and objectives of a research, the choice of research methodology to be used cannot be overemphasised. In social science research, there are three research methodologies namely quantitative, qualitative and mixed methods [1]. Qualitative research has been described as an inquiry process of understanding, based on a distinct methodological tradition of inquiry that explores a social or human problem [1-2]. It has been mentioned that the basic characteristics of qualitative research include natural setting, researcher as key instrument, multiple sources of data, inductive analysis, participants' meanings, emergent design, reflexivity and holistic account $[1,3]$.

Therefore, in an attempt to successfully answer the research question it is indispensable to identify the appropriate research design that will guide the study. According to [4] research design as a plan or blueprint of how a research will be conducted. It is also referred to as the researcher's plan or strategy for the study, which includes the method to be used, what data will be gathered, where, how, and from whom [5]. Similarly, [1, 6] mentioned that there are five different approaches available to qualitative researchers including case study, grounded theory, ethnography, phenomenology and narrative research or inquiry. The rationale being that these research designs are well used and popular 
in social sciences [1]. Based on the descriptions in the foregoing, the aim of this paper is to focus on the research methodology aspects of case study as a research approach and its relevance in tourism destination branding research specifically on a single case study (SCS) context. Case study and SCS have been widely used in tourism research and destination branding respectively. However, despite the ample evidences from the literature, case study research methodology has long been viewed as a weak strategy among the social science researchers [7]. Case study have been criticised for lack of rigour in terms of sampling because in qualitative case study approach sampling is not random. Other weaknesses such as flexibility in terms of data collection method, data analysis, researcher lack of social experience, lack of rigour, reliability, validity, credibility of the research findings and generalisations of a SCS has remained a controversial issues [8]. These views are misleading and this paper attempts to reduce these misconceptions and gaps in the literature. Hence, there is a need to provide ample evidences from the tourism literature that case studies have been widely used in tourism research and rationales for using qualitative single case study.

\section{Literature review}

Case study method has a long distinguished history across different disciplines [6]. According to [9], the origin of case study studies can be traced to sociology and anthropology. Furthermore, [9] cited the French sociologist LePlay's study of families, anthropologist Malinowski's study of the Trobriand Islands, and the case studies of the University of Chicago Department of Sociology from the 1920s and 30s through the 1950s (for example, Thomas and Znaniecki's 1958 study of Polish peasants in Europe and America) as historical background of qualitative case study research.

\subsection{Case study in tourism research}

There are different definitions on case study. However, for the purpose of this paper, the case study definition developed by [10] will be adopted because the contents are consistent with the aim of this paper. According to [10], Case study has been defined as an empirical inquiry that investigates or find out about a phenomenon within its real-world context, when the boundaries between phenomena and context are but clearly evident, in which multiple data sources are used [10]. This definition suggests that case study is an empirical research to indicate it involves data collection and data analysis which represents major features of other research approaches. Moreover, multiple sources of data collection are required in case study. According to [10], there are six sources of evidence in conducting qualitative case studies including interviews, direct observations, archival records, documents, participant observation, physical artefacts. This is because to develop a tourism destination brand, it involves more than a single individual or one entity (multiple stakeholders) in contrast to other qualitative research methods. For example, phenomenology study focuses on conducting interview with between 5 to 25 people [11]. Grounded theory enables the researcher to build a theory from the study context [1]; and interviews are conducted with 20 to 30 people to achieve detail in the theory [6]. Likewise in narrative research it involves the researcher to study the lives of individuals by asking them to provide stories of their lives. In addition, ethnography requires the researcher to study a particular group in a natural setting over a prolonged period of time [1].

Furthermore, case study method is used in tourism destination branding because of the need and desire to understand complex social phenomena. A very good example is how a remote rural tourism destination can be branded. Moreover, case study method is employed so that the study context can be explained in a logical manner that links the empirical data to the study's preliminary research up to the conclusion stage of the research [12]. Similarly, [10, 13] stated that the case study design is the most appropriate in situations in which it is impossible to separate the phenomenon being studied from its context (i.e. the tourist, tourism attractions, and the tourism destination). Today, qualitative case study has been widely used in destination branding [14]; and tourism studies [7] Therefore, based on the arguments outlined in the foregoing, it appears case study will continue to receive academic attention in tourism destination branding with specific reference to SCS. Therefore, 
it makes sense to briefly dwell on the rationales for using single case study in tourism destination branding context.

\subsection{Rationales for single case study in tourism destination branding}

There are two types of case study designs namely; single and collective or multiple case studies [10, 12-13]. A single-case study or design is ideal for studying unique cases, to confirm a theory or for cases where the researcher did not have access to before [10,12]. Multiple-case designs are more suited when the researcher is interested in using more than one case to obtain data from different sources and draw conclusions [12]. The single case study is suitable if the study context is a unique or extreme tourism destination (e.g. remote/rural destination). This claim is in harmony with Yin [10,1213] that one of the major reasons for conducting a single case study is when there is an extreme case or unique case to investigate. There are other rationales for using single-case study these include; critical case and revelatory case [10]. Single case study that involved unique and revelatory case has been applied in tourism destination branding [15-16].

The use of single case study will enable the researcher to uncover the distinct features or attributes of the phenomenon (for example, the stakeholders' involvement, destination attractions and potential critical success factors) requires in building destination brand. This assertion concurred with [12] that single case study is the most appropriate method for understanding a new phenomenon from in-depth perspective and it provides rich data gathering. This is crucial to provide answers to the research questions, achieving the main aim and objectives of the study. Furthermore, single case study is used by researchers because of the complexity involved in developing a destination brand [17-19]; and specifically in rural tourism destination. This is due to several factors such as language, differences in tourist attractions at rural destinations, different group of stakeholders, limited number of tourist arrivals, and accessibility of the researcher to the study context. In a nutshell, single case study is adopted where the primary purpose is to explore the particularity, the uniqueness of the event, or it could be a nation, city, village or the problem within its social context [19].

\section{Methodology}

This paper has adopted content analysis of the literature on tourism, destination branding, place branding and rural tourism destinations to support the arguments that a single case study is mostly used by tourism and destination branding researchers and practitioners alike. Content analysis is widely used to analyse journal articles and written communication that uses a set of systematic procedures which assists the researcher to make valid inferences in terms of interpreting meaning from the content of text data [20]. Similarly, content analysis have been used in tourism and destination branding by past studies such as [7, 21-24]. Moreover, the following criteria were used for the selection of extant literature review. First of all the researchers read the titles, abstracts and subtitles within the selected articles. The title of the literature must be focused on tourism, place branding, destination branding, rural tourism destinations and more importantly with themes suggestive of case studies and SCS respectively. Additionally, research notes and book chapters were not considered. In other words, only full journal articles were selected and reviewed. This is so in order to benefit from the methodological approaches used in journal papers.

Furthermore, the Berg's eight stage model of qualitative consent analyses were used [25]. Notably, three stages in the model were relevant to this paper. These include the following: (1) Decide on the level of analysis; (2) Decide on the number of characteristics to be investigated; and (3) Decide whether to code for occurrence or frequency or both. Besides, in order to describe, interprets and explain the dimensions that emerged from the elements recorded a conceptual analysis which is inductive in nature was adopted [24-25]. In conceptual analysis, concepts that are relevant to tourism destination branding, place branding, and rural tourism were selected and scrutinised in order to ascertain the frequency of occurrences recorded. For example, terms like the study context or destination and theme or focus of the studies were identified and matched appropriately in terms of 
whether it is multiple case studies or single case study. Findings that are specific to single case study is presented in Table 1.

\section{Findings and discussion}

\subsection{Case study in tourism research}

The results of the review of literature indicate that case studies are widely used in tourism studies. This is corroborated by previous studies [7]. For example [7] reviewed top-rated tourism journals such as Annals of Tourism Research (3) Journal of Travel Research (15), Tourism Analysis (10) and Tourism Management (48). In total 76 case studies were found in these journals from 2000-2004. It was also found that 36 or $47 \%$ of these studies adopted single case study; while two and multiple cases accounted for 20 or $26.5 \%$ each. These findings confirmed previous claim that tourism research has been dominated by case studies [26]. Likewise, most publication from 2004 till present moment follow the same pattern and specifically single case study is mostly used in tourism destination branding context.

\subsection{Single case study in tourism destination branding}

The purpose of this section is to provide ample evidences that single case study dominated tourism destination branding research. For example, [14] conducted a review of 74 destination branding literature from the first 10 years (1998-2007) of destination branding publications by 102 authors. It was found that 22 of the destination branding literature used single case study while 4 adopted multiple case studies. This finding indicates that arguments against the single case study is very weak. Therefore, some of the tourism destination branding literature we reviewed for this paper which have adopted single case study approach is presented in Table 1.

Table 1. Analysis of single case study in tourism destination branding $(1998-2014)$

\begin{tabular}{lll} 
Source & Case/Destination & Theme \\
\hline 14 & 22 (single case) & Brand strategy development (15 nos) \\
14 & 4 (multiple cases)* & Band strategy(3)/national identity (1) \\
16 & New Zealand & Destination branding and the role of the stakeholders \\
15 & Dubai, UAE & Destination branding strategy. \\
27 & Gold Coast, Australia & Stakeholders' power in destination branding \\
28 & Calabar, Nigeria & Branding cultural festival \\
29 & Canada & Tourist experience \\
30 & Finland & Destination brand identity and values system \\
31 & Forest of Dean, UK & Destination image analysis \\
32 & Alexandria, Egypt & Perception of destination branding measures \\
33 & North-East Victoria & Destination brand identity and values \\
34 & Australia & \\
35 & Oklahoma State, USA & Branding and destination image. \\
36 & Czech Republic & Destination marketing and branding strategy \\
37 & Mauritius & Push and pull factors \\
38 & Wales, UK & Destination marketing KPI \\
39 & Mauritius & Brand image of a small island \\
40 & Bangladesh & Destination image and tourism \\
41 & Kuala Lumpur & Branding strategies and identities \\
42 & Monmouthshire, Wales & Partnership \\
\hline & Chatham Islands, NZ & Sense of place \\
\hline
\end{tabular}




\subsection{Strategies of using case study approach}

This paper has reviewed a set of case study and single case study from tourism literature as presented in the foregoing. As mentioned earlier in the preceeding sections that there are arguments against the use of case study. The purpose of this paper is to reduce the gap in the tourism literature and the misconceptions that case study and in particular that single case study is weak conceptually. These misconceptions are misleading and may impact negatively on the application of case study by academic tourism researchers [7]. This paper finds that case study and SCS both have their strengths and weaknesses. Nevertheless, this can be managed effectively by the researchers to justify the credibility of a research outcome. Therefore, this paper argues that there are strategies to manage potential or weaknesses of case study and SCS approach. For example, [43] provides four techniques for analysisng evidence in both multiple case studies and SCS. These include the following: (1) pattern-matching which involves making a comparison of an empirically based pattern with a predicted one. This is to validate the internal validity of the analytical statements. (2) explanationbuilding which has seven steps but notably is the making of an initial theoretical statement about a problem being investigated and then comparing the findings of an initial case against such a statement. (3) time-series analysis, which is to investigate or exmine 'how and why' questions about the relationship of phenomena over time. (4) program logic models, which match 'cause-effect patterns between independent and dependent variables'. Furthemore, methodological measures is an important strategy in case study and SCS. This section identifies four widely used design tests known as case study tactics that can be adopted to judge the quality of the research design in terms of validity and reliability [13]. This is presented in Table 2 .

Table 2. Case study tactics for four design tests

\begin{tabular}{|l|l|l|}
\hline Tests & Case & Stage of research in which tactic occurs \\
\hline $\begin{array}{l}\text { Construct } \\
\text { Validity }\end{array}$ & $\begin{array}{l}\text { Multiple sources of evidence and establish } \\
\text { chain of evidence to converge (triagulation of } \\
\text { data sources) }\end{array}$ & $\begin{array}{l}\text { Data collection - interviews, observation, } \\
\text { documentary evidence }\end{array}$ \\
\hline Internal Validity & Pattern matching & $\begin{array}{l}\text { Data analysis - see the paragraph 1 of this } \\
\text { section }\end{array}$ \\
\hline External Validity & Replication logic in multiple-case studies & Research design \\
\hline Reliability & Case study protocol and data base & Data collection \\
\hline
\end{tabular}

Source: Adapted from [13]

\subsection{Validity, reliability and generalisability of qualitative single case study}

Moreover, academic researchers often criticised the credibility of qualitative case studies especially those who view reality from the positivism paradigm. Based on this view, credibility interrns of reliability, validity and generalisation have been questioned over time. Validity refers to the degree to which a study accurately reflects or asseses the specific concept that the researcher is attempting to measure [44]. While reliability refers to how consistent a meauring device is, meaning the measurement is said to be reliable or consitent if the meausrement can produce similar results if used again in similar circustances [44]. Therefore, to achieve reliability in case studies, [12, 43] suggest the development of the case study protocol as a major way of increasing the reliability of case study research and is intended to guide the researcher in carrying out the data collection from a "single case" study. Likewise, [12] outlined the following as the case study protocol including: 1) an overview of the case study project - this study will attempt to communicate to the reader the main aim and objectives of the case study; 2) field procedures - i.e. how the data will be collected and access to the study context; 3) case study questions research questions that will remind the researcher data to be collected and the potential respondents; and a guide for case study report such as case outline, format for the data and documentary information.

Furthermore, generalisability relates to findings that are capable of being tested by others using the same measures and with equivalent sample [44]. The generalisability of a single case study 
remains one of the most debated topics in case study methodology [8,45]. However, [46] mentioned that instead of using these terms (validity, reliability and generalisability) qualitative researchers may now incorporate the use of credibility, transferability, and conformability". This is said to be an alternative means to the well known internal and external validity, reliability and objectivity. These concepts were explained in simplest form by [47] that credibility is noted by the participants' level of truth; transferability depends on the accuracy of the researchers means of securing data sensitivity, description and understanding of the data collected; dependability deals with the possibility of changes within the research process where 'repeatability' (traditional) curves to the "how changes affect the way the research approached the study' and finally conformability, researchers may document their findings by rechecking the data obtained or collected during the research. Similarly, transferability is the process by which we can infer and interpret from a given research outcome to other situations [44]. Research findings under this approach can act as a point of reference and comparison in other circumstances [44]. Therefore, this kind of transfer is commonly associated with interpretative research and qualitative data.This argument is consistent with [33] that given the exploratory nature of a case study research, generalisability of the findings was not an objective. This was also supported by [48] that where a case study adopts an interpretivist - constructivist approach the "intentions were to understand the meanings constructed by human beings through their interactions with others and the surrounding world".

\section{Conclusion and implications}

We would like to conclude that it is not the objective of this paper to argue that single case study is the most suitable approach for tourism destination branding research. However, the paper attempts to bridge the existing gap as stated in the previous sections. There are several high profile studies from top-rated journals, book chapters, thesis and dissertations from postgraduate scholars that are not featured in this paper. Therefore, we strongly recommend that future studies should focus on the examination of the profile of the researchers and geographical location where these studies were conducted. This is necessary in order to ascertain the quality and acceptability of these studies. Based on the above there are criteria to be fulfilled to justify the application of single case study to tourism destination branding research. Once these criteria and the methodological issues are met, single case study is a valuable method to conduct empirical studies in tourism and destination branding context.

In conclusion, theoretical implication indicates that single case study is an empirical enquiry arises due to the need to understand the complex phenomena within the real life context leading to indepth data collection involving triangulation of data sources. Similarly, managerial implication suggests that single case study is widely used in the industry and it will continue to enjoy patronage among the tourism destination branding practitioners.

\section{Acknowledgement}

The funding for this project was made possible through a research grant obtained from the Malaysian Ministry of Education, under the Long Term Research Grant Scheme (LRGS), 2011. Reference no. JPT.S (BPKI) 2000/01/015JId.4(67).

\section{References}

1. J. W. Cresswell, Research design: qualitative, quantitative, and mixed methods. approaches $4^{\text {th }}$ ed., Thousand Oaks, CA: Sage Publications Inc. (2014).

2. J. W. Cresswell, Qualitative Inquiry and Research Design: Choosing among five traditions. Thousand Oaks, CA; Sage (1998).

3. C. Marshall, G.B. Rossman. Designing qualitative research $\left(5^{\text {th }}\right.$ ed.). Thousands Oaks, CA: Sage (2011). 
4. J. Mouton, The practice of social research. Cape Town: Oxford University Press (2001).

5. D. Ary, I. C. Jacobs, A. Razavieh, C. K. Sorensen, Introduction to research in education, New York: Centage Learning (2010).

6. J. W. Cresswell, Qualitative inquiry and research design: choosing among five approaches $2^{\text {nd }}$ ed., Thousand Oaks, CA; Sage (2007).

7. H. Xiao, J. Smith, L.J. (2006). Case studies in tourism research: a state-of-the-art analysis, Tourism Management, 27, 738-749 (2006)

8. H. Simons, The paradox of case study, Cambridge Journal of Education 26, 2, 225-240 (1996)

9. J. Hamel, S. Dufour, D. Fortin, Case study methods. Newbury Park, CA: Sage (1993).

10. R.K.Yin, Case study research: design and methods (5 $5^{\text {th }}$ ed.). Thousand Oaks California: Sage Publications, Inc. (2012).

11. D.E. Polkinghorne, Phenomenological research methods. In: R.S. Valle \& S. Halling (Eds.), Existential-Phenomenological Perspectives in Psychology, New York: Plenum Press. 41-60 (1989)

12. R.K.Yin, Case study research: design and methods $4^{\text {th }} e d$., Thousand Oaks California: Sage Publications, Inc (2009).

13. R.K. Yin, Case study research: design and methods $3^{\text {rd }}$ ed., Thousand Oaks, California: Sage Publications, Inc. (2003).

14. S. Pike, Destination brand positions of a competitive set of near-home destinations. Tourism Management, 30, 6, 857-866 (2009)

15. M.S. Balakrishnan, Dubai - a star in the east. Journal of Place Management and Development 1, 1, 62-91 (2008)

16. N. Morgan, A. Pritchard, R. Piggott, Destination branding and the role of the stakeholders: the case of New Zealand. Journal of Vacation Marketing. 9, 3, 285-299 (2003) doi: $10.1177 / 135676670300900307$.

17. N. Morgan, A. Pritchard, R. Piggot, New Zealand, 100\% pure. the creation of a powerful niche destination brand. Journal of Brand Management, 9, 4-5, 335-354 (2002)

18. C-S. Ooi, B. Stoeber, Authenticity and place branding: the arts and culture in branding Berlin and Singapore. In: B. T. Knudsen and A. M. Waade eds., Re-investing authenticity: tourism, places and emotions. Bristol: Channel View Publications. 66-79 (2010)

19. H. Simons, Case study research in practice. London: Sage Publications limited (2009).

20. M. Puvenesvary, R.A. Rahim, R.S. Naidu, M. Badis, N.F.M Nayan, N.H.A. Aziz. Qualitative research: Data collection and data analysis techniques. Sintok Universiti Utara Malaysia Press (2011).

21. G. Marzano, N. Scott. Consistency in destination branding: the impact of events. Global Events Congress and Event Educators Forum, Brisbane, Australia, (2006) September 27-29, 196-205 (2006)

22. S. Pike, Destination brand positioning slogans - towards the development of a set of accountability criteria. Acta Turistica, 16, 2, 102-124 (2004)

23. G. Lee, L.A. Cai, J.T. Leary. WWW.Branding.State.US: an analysis of branding- building elements in the US State Tourism Websites. Tourism Management, 27, 815-828 (2005)

24. L. B. Berg, Qualitative research methods for social sciences $5^{\text {th }}$ ed., Boston: Pearson (2004).

25. T.F. Carney, Content Analysis: a technique for systematic inference from communications. London: B.T. Batsford Limited (1972).

26. A. Franklin, M. Crang, The problem with tourism and travel theory. Tourism Studies, 1, 1,5-22 (2001)

27. G. Marzano, N. Scott, Power in destination branding. Annals of Tourism Research, 36, 2, 247 267 (2009)

28. B.B. Esu, V. M.E. Arrey. (2009). Branding cultural festival as a destination attraction: a case study of Calabar carnival festival. International Business Research, 2, 3, 182-192 (2009)

29. S.Hudson, J. R.B. Ritchie, Branding a memorable destination experience. the case of 'brand Canada'. International Journal of Tourism Research, 11, 217-228 (2009) doi: 10.1002/jtr.720. 
30. S. Saraniemi, From destination image building to identity-based branding. International Journal of Culture, Tourism and Hospitality Research, 5, 3, 247-254 (2011)

31. N. Greaves, H. Skinner, The importance of destination image analysis to UK rural tourism. Marketing Intelligence and Planning, 28, 4, 486-507 (2010)

32. S.B. Hassan, M.S.A. Hamid, H.A. AL Bohairy, Perception of destination branding measures: $a$ case study of Alexandria destination marketing organizations. Int. J. of Euro Mediterranean Studies, 3, 2, 269-288 2010)

33. F. Wheeler, W. Frost, B. Weiler, Destination brand identity, values and community: a case study from rural Victoria Australia. Journal of Travel and Tourism Marketing, 28, 1, 13-26 (2011)

34. H. Qu, L.M. Kim, H.H. Im, A model of destination branding: integrating the concepts of the branding and destination image. Tourism Management, 32, 3, 465-476 (2011)

35. M. Palatkova, The 7-S-McKinsey model: an implementation tool of a destination marketing strategy in the Czech Republic. Global Management Journal, 3, 1/2, 44-54 (2011)

36. C. Ryan, G. Prayag, The relationship between the 'push' and 'pull' factors of a tourist destination: the role of nationality - an analytical qualitative research approach. Current Issues in Tourism, 14, 2, 121-143 (2011)

37. N. Morgan, E. Hastings, A. Pritchard, Developing a new DMO marketing evaluation framework: the case of visit Wales. Journal of Vacation Marketing, 18, 1, 73-89 (2012)

38. P. Naidoo, P. Ramseook-Munhurrun, The brand image of a small island destination: the case of Mauritius. Global Journal of Business Research, 6, 1, 55-64 (2012)

39. I. Zahra, Destination image and tourism: a case of Bangladesh. European Journal of Business and Management 4, 6, 18-27 (2012)

40. F. A. L. Bouchon, Truly Asia and global city? Branding strategies and contested identities in Kuala Lumpur. Place Branding and Public Diplomacy, 1-13. doi:10.1057/pb.2013.21 (2013)

41. C. Haven-Tang, D. Sedgley, Partnership working in enhancing the destination brand of rural areas: a case study of made in Monmouthshire, Wales, UK. Journal of Destination Marketing and Management. 3, 59-67 (2014)

42. A. Campelo, R. Aitkem, M. Thyne, J. Gnoth, Sense of place: the importance of destination branding. Journal of Travel Research 53, 2 (2014) 154-166. doi:10.1177/0047287287513496474

43. R.K. Yin, Case study research : Design and methods. $2^{\text {nd }}$ ed. Thousand Oaks, CA: Sage.

44. R. Ahmad, H. Usop, Conducting research in social sciences, humanities economics and management studies - A Practical Guide. Sarawak: RS Group Publishing House (2011).

45. M.M. Kennedy, Generalising from single case studies, Evaluation Quartely 3, 4, 661-678 (1979)

46. G. Jennings, Tourism research $2^{\text {nd }}$ ed. Milton, Australia: Wiley \& Sons, (2010).

47. W. Trochim, Qualitative Validity, Retrieved from : http://www.socialresearchmethods.net/kb

48. R. Aitken, A. Campelo, The four r's of place branding. New Zealand : University of Otago (2009). 